Special issue of the 3rd International Conference on Computational and Experimental Science and Engineering (ICCESEN 2016)

\title{
Trend Detection in Climate Change Indicators Using Non-Parametric Statistics: A Case Study of Abu Dhabi, United Arab Emirates
}

\author{
A. Basarir ${ }^{a, *}, \mathrm{H} \cdot \operatorname{Arman}^{a}, \mathrm{~S}_{\operatorname{Hussein}^{a}}, \mathrm{~A} \operatorname{Murad}^{a}, \mathrm{~A} \cdot \operatorname{Aldahan}^{a}$ \\ AND M. ABDUlla Al-ABRI ${ }^{b}$ \\ ${ }^{a}$ United Arab Emirates University, Al Ain, UAE \\ ${ }^{b}$ National Center of Meteorology and Seismology, Abu Dhabi, UAE
}

This study focuses on detecting trends for climate change indicators, such as average monthly temperature, rainfall, humidity, and wind speed for fourteen stations located between Al Ain and Abu Dhabi cities of the United Arab Emirates. Mann-Kendall non-parametric test was run on monthly time series data for the period 2003-2015 with consideration of seasonality. Significant increasing/decreasing trends in rainfall (for four stations), humidity (for six stations), and wind speed (for nine stations) were detected while no significant trend was observed in temperature for all stations.

DOI: $10.12693 /$ APhysPolA.132.655

PACS/topics: 92.70.Kb, 92.05.Df

\section{Introduction}

Trends in climate change have been detected globally in different forms, such as downpours, storms, rising temperature and sea level, retreating glaciers, etc. Rainfall, $53^{\circ} 0^{\circ} 0^{\prime \prime} \mathrm{E}$

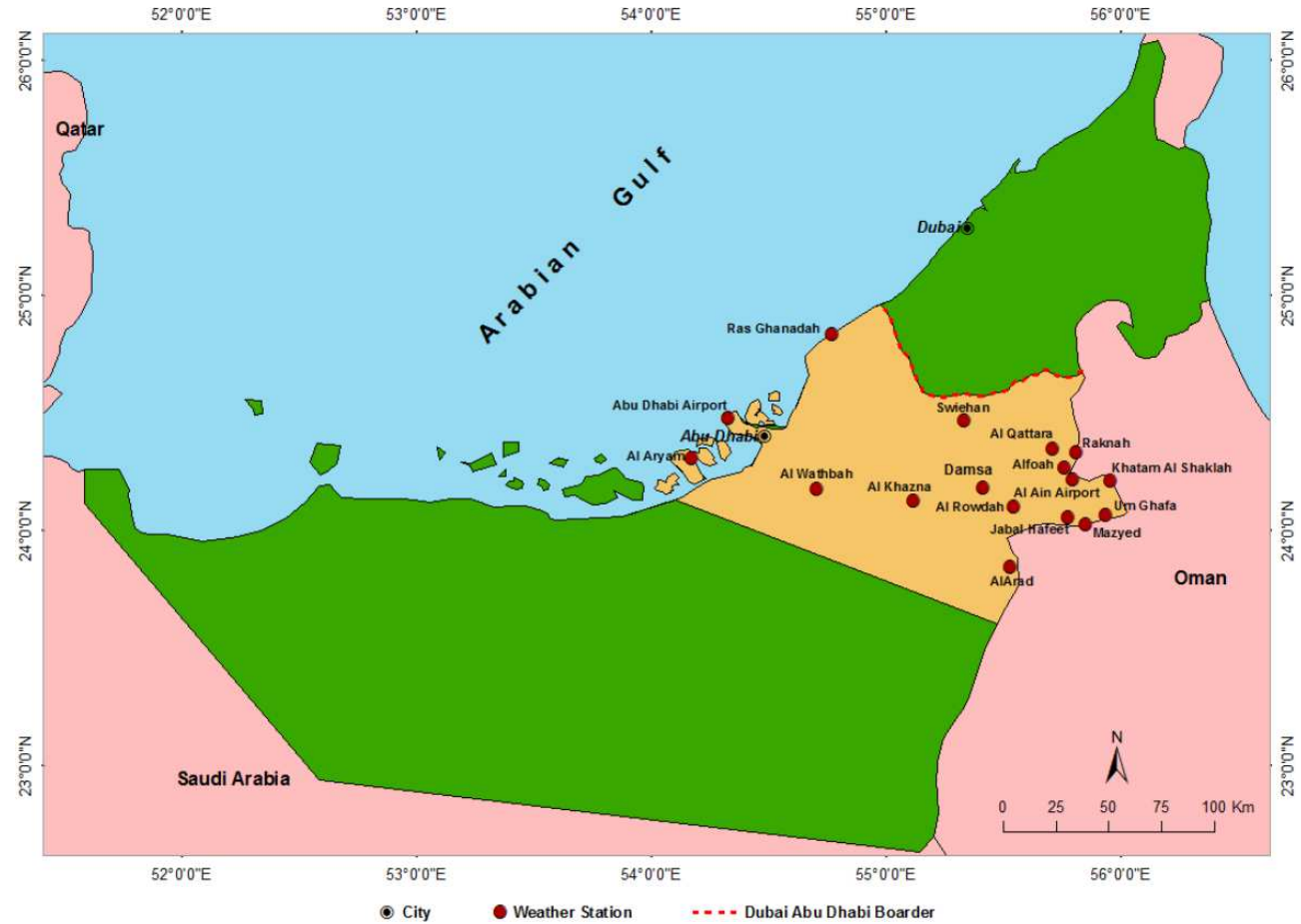

Fig. 1. Location map of the study area.

with average summer temperature reaching up to $48^{\circ} \mathrm{C}$ and humidity up to $100 \%$ in coastal cities. Average

monthly rainfall pattern varies widely throughout the

\footnotetext{
*corresponding author; e-mail: abasarir@uaeu.ac.ae
}

temperature, humidity and wind speed are commonly used as climate change indicators [1]. The United Arab Emirates (UAE) is located in the eastern part of the Arabian Peninsula (Fig. 1). This region has an arid climate, year and over $80 \%$ of the annual rainfall occurs during the winter season. The monsoon winds blowing across the UAE are stronger in the spring and late summer months, and are of two types: the northern dry wind, which helps mitigate the temperature, as far as it is not laden with dust and the eastern wind, which is usually very humid [2-4]. 
The statistical analyses of monthly weather data have not been found in the literature for the study area (Fig. 1). The Mann-Kendall (M-K) approach was applied here to expose possible weather/climatic changes. This statistical technique has been applied successfully in other regions [1,5-11] and would be a challenge for the climate time series in the Arabian Peninsula, which is expected to experience increasing temperature in the future, as suggested by the Intergovernmental Panel on Climate Change (IPCC) [4].

\section{Methodology}

The monthly time series data of temperature, rainfall, humidity, and wind speed for the January, 2003July, 2015 period were obtained from UAE National Center of Meteorology and Seismology (NCMS) for fourteen stations located in Abu Dhabi Emirate (Fig. 1) [12].

The M-K nonparametric test is one of the mostly utilized techniques in analysis of climatic time series data, particularly for data without normal distribution [1, 5-8]. In addition, the test has low sensitivity for sudden breaks in the time series [13]. According to the null hypothesis $\mathrm{H}_{0}$ of the test, there is no trend and the data are randomly and independently ordered. The judgment of null hypothesis is tested by alternative hypothesis $H_{1}$, which assumes the existence of a trend [14].

Using the XLSTAT 2016 plug-in for Microsoft Excel, the monthly percentage contributions of temperature, rainfall, humidity, and wind speed over January, 2003
- July, 2015 period were analyzed by using M-K trend test, shown in Eq. (1) [8].

$$
S=\sum_{k=1}^{n-1} \sum_{j=k+1}^{n-1} \operatorname{sign}\left(x_{j}-x_{k}\right),
$$

where

$$
\operatorname{sign}\left(x_{j}-x_{k}\right)=\left\{\begin{aligned}
1, & \text { if } x_{j}-x_{k}>0, \\
0, & \text { if } x_{j}-x_{k}=0, \\
-1, & \text { if } x_{j}-x_{k}<0,
\end{aligned}\right.
$$

and $x_{1}, x_{2}, x_{3} \ldots x_{n}$ represent $n$ data points, $x_{j}$ represents the data point at time $j$ and $S$ is the M-K statistics.

\section{Results and discussion}

The results of $\mathrm{M}-\mathrm{K}$ test, conducted on the time series data, are given in Table I. There were positive $S$ values for temperature in thirteen out of fourteen stations, but none of them was statistically significant enough to reject the null hypothesis. Thus, there is no trend and the temperature data, which seems to be randomly and independently ordered. Increasing trends in rainfall for four out of fourteen stations, Al Faqa, Al Foah, Mazyed, and Swiehan were detected. The trend for humidity indicates an increase at Al Faqa, Al Foah, Al Wathbah, and Al Khazna and a decrease at Abu Dhabi and Al Ain stations. Trends of wind speed were increasing in Jabal Hafeet, Mazyed, Al Khazna, and Abu Dhabi; and decreasing in Saih Al Salem and Swiehan stations.

TABLE I

The results of Mann-Kendall test for monthly average temperature, rainfall, humidity, and wind speed for stations located in Abu Dhabi.

\begin{tabular}{c|c|c|c|c|c|c|c|c}
\hline \hline & \multicolumn{2}{|c|}{ Temperature } & \multicolumn{2}{c|}{ Rainfall } & \multicolumn{2}{c|}{ Humidity } & \multicolumn{2}{c}{ Wind speed } \\
\hline & $\begin{array}{c}\text { Mann } \\
\text { Kendall } \\
\text { Statistics } \\
\text { Stations }\end{array}$ & $\begin{array}{c}\text { p-value } \\
\text { (Two-tailed) }\end{array}$ & $\begin{array}{c}\text { Mann } \\
\text { Kendall } \\
\text { statistics } \\
\text { (S) }\end{array}$ & $\begin{array}{c}\text { Mann } \\
\text { p-value } \\
\text { (Two-tailed) }\end{array}$ & $\begin{array}{c}\text { Mann } \\
\text { Kendall } \\
\text { statistics } \\
\text { (S) }\end{array}$ & $\begin{array}{c}\text { p-value } \\
\text { (Two-tailed) }\end{array}$ & $\begin{array}{c}\text { Kendall } \\
\text { statistics } \\
\text { (S) }\end{array}$ & $\begin{array}{c}\text { p-value } \\
\text { (Two-tailed) }\end{array}$ \\
\hline Al Faqa & 269 & 0.666 & 1863 & 0.002 & 2203 & 0.000 & -147 & 0.814 \\
Al Shiweb & 233 & 0.709 & 1059 & 0.086 & 889 & 0.153 & -2667 & $<0.0001$ \\
Alarad & 341 & 0.584 & 10 & 0.988 & 181 & 0.772 & 341 & 0.584 \\
Alfoah & 425 & 0.495 & 1671 & 0.005 & 2143 & 0.001 & -2893 & $<0.0001$ \\
Alwathbah & 175 & 0.780 & 1 & 1.000 & 1383 & 0.026 & -12 & 0.986 \\
Jabal Hafeet & -133 & 0.832 & 468 & 0.447 & 723 & 0.245 & 3953 & $<0.0001$ \\
Khatam Al Shaklah & 367 & 0.556 & 823 & 0.169 & 737 & 0.236 & -3155 & $<0.0001$ \\
Mazyed & 339 & 0.587 & 1213 & 0.039 & 807 & 0.195 & 1241 & 0.046 \\
Raknah & 435 & 0.485 & 403 & 0.505 & 807 & 0.195 & 379 & 0.543 \\
Saih Al Salem & 569 & 0.361 & 823 & 0.156 & -139 & 0.824 & -5083 & $<0.0001$ \\
Swiehan & 677 & 0.277 & 1513 & 0.008 & 473 & 0.448 & -1281 & 0.039 \\
Al Khazna & 287 & 0.645 & 298 & 0.616 & 1519 & 0.015 & 1317 & 0.034 \\
Abu Dhabi Airport & 278 & 0.656 & 127 & 0.797 & -1208 & 0.052 & 2024 & 0.001
\end{tabular}


Furthermore, a close relationship between some of the indicators was realized. Both the rainfall and the humidity data illustrate increasing trends for Al Faqa and Al Foah stations, as expected. On the other hand, $\mathrm{Al}$ Foah and Sweihan stations reveal a negative relationship in rainfall and wind speed trends. Thus, rainfall seems to have a negative effect on wind speed of the region. A negative relationship is also noticed between humidity and wind speed of Al Foah and Abu Dhabi stations. Consequently, the increasing trend of wind speed may retard the humidity front from pushing into the inner parts (inland) of the study region.

\section{Conclusions}

The M-K statistical analysis of meteorological time series data from fourteen stations in Abu Dhabi Emirate showed significantly increasing rainfall trends in four stations, increasing/decreasing humidity trends in six stations, and wind speed in nine stations. The trends of temperature were not significantly varying for all stations. These results suggest that detected short term weather/climate variability may vary on local scale when using monthly data. Generally, the inland stations appear to reflect a better relationship between wind speed and humidity than the coastal station.

\section{References}

[1] A.R. Murumkar, D.S. Arya, Am. J. Climate Change 3, 60 (2014).

[2] State of Environment of the United Arab Emirates Report, Ministry of Environment and Water, Abu Dhabi 2015 .
[3] H. Arman, Int. J. Global Warm. 8, 1 (2015).

[4] Climate Change 2013 The Physical Science Basis, Contribution of working group I to the fifth assessment report of the intergovernmental panel on climate change, Ed. T.F. Stocker, 2013.

[5] S.S. Chinchorkar, F.G. Sayyad, V.B. Vaidya, V. Pandye, MAUSAM 66, 1 (2015).

[6] N. Karmeshu, Trend detection in annual temperature \& precipitation using the Mann Kendall test - A Case Study to Assess Climate Change on Select States in the Northeastern United States, 2012.

[7] T. Partal, E. Kahya, Hydrolog. proc. 20, 2011 (2006).

[8] B. Mapurisa, D. Chikodzi, Am. J. Climate Change 3, 50 (2014).

[9] R.M. Hirsch, J.R. Slack, R.A. Smith, Water Resourc. Res. 18, 107 (1982).

[10] J.R. Lanzante, S.A. Klein, D.J. Seidel, J. Climate 16, 241 (2003).

[11] M. Rebetez, M. Reinhard, Theoret. Appl. Climatol. 91, 27 (2008).

[12] Climate Data for Temperature, Rainfall, Humidity, and Wind Speed, NCMS and DMCD, Abu Dhabi 2015.

[13] H. Tabari, S. Marofi, A. Aeini, P.H. Talaee, K. Mohammadi, Agricult. Forest Meteorol. 151, 128 (2011).

[14] B. Önöz, M. Bayazit, Turk. J. Engin. Environ. Sci. 27, 247 (2003). 